\title{
ROAD AMBULANCES: WORKING CONDITIONS OF PARAMEDICS - PILOT STUDIES
}

\section{SYLWIA BĘCZKOWSKA ${ }^{1}$, IWONA GRABAREK ${ }^{1}$, SŁAWOMIR PILIP², LESZEK SZPAKOWSKI ${ }^{3}$, and ROBERT GAŁAZZKOWSKI²}

${ }^{1}$ Warsaw University of Technology, Warsaw, Poland

Faculty of Transport, Division of Information and Mechatronic Systems in Transport

${ }^{2}$ Medical University of Warsaw, Warsaw, Poland

Department of Emergency Medical Services

${ }^{3}$ Emergency Medical Rescue Service, Siedlce, Poland

\begin{abstract}
Objectives: The article presents the results of selected pilot studies conducted in medical ambulances. Their aim was to determine the working conditions and identify troublesome factors accompanying the performance of basic medical procedures by rescue teams. Material and Methods: The study of working conditions was carried out in Mercedes-Benz ambulances, type S and P. Fifty-one paramedics of the Emergency Medical Rescue Service in Siedlce took part in the research. The questionnaire expert survey method and the direct observation method were used. Results: As a result of the applied research methods, knowledge was gained on the irregularities and difficulties that occur at the workplace of a paramedic, i.e., in an ambulance, including the lack of access to essential elements of medical equipment and their different location inside the vehicle, and the diversity of solutions for the spatial structure of ambulances, which all cause difficulties at work. Research has shown that paramedics take, on average, 33 min to familiarize themselves with the location of equipment in an ambulance other than the one in which they are usually on duty. There was no correlation between the lifeguard's length of service and the time necessary for getting acquainted with the equipment, which was studied using Pearson's correlation coefficient. In the study, rescuers also pointed to musculoskeletal ailments, mainly spinal pains resulting from taking forced positions during medical activities in an ambulance. Conclusions: The results obtained constitute the basis for the author's methodology of complex research aimed at defining the ergonomic recommendations necessary in the modification process of the operated medical fleet. The next step will be to formulate uniform guidelines for the construction of medical compartments of ambulances, the application of which will lead to the unification of their spatial structure regardless of the vehicle brand. Int J Occup Med Environ Health. 2020;33(1):91-105
\end{abstract}

Key words:

questionnaire survey, paramedics, occupational hazard, ergonomic, musculoskeletal discomfort, ambulances

\section{INTRODUCTION}

Medical Emergency Rescue Teams (MERTs) are units of the State Medical Rescue System, which provide pre-hospital medical assistance to persons in an emergency medical condition. This concerns both life-threatening condi- tions of an internal origin, e.g., acute coronary syndrome or brain stroke, as well as sudden injuries, e.g., those sustained in a traffic accident. In addition, emergency medical teams provide medical services in the case of childbirth and deal with patients with mental disorders.

Received: May 8, 2019. Accepted: October 24, 2019.

Corresponding author: Sylwia Bęczkowska, Warsaw University of Technology, Faculty of Transport, Division of Information and Mechatronic Systems in Transport, Koszykowa 75, 00-662 Warsaw, Poland (e-mail: bes@wt.pw.edu.pl). 
The state of a sudden health risk is defined as a condition consisting in a sudden or short-time predicted occurrence of symptoms of health deterioration, the immediate consequence of which may be a serious impairment of bodily functions, an injury or the loss of life, requiring immediate medical rescue and treatment [1]. In Poland, as at December 31, 2017 [2], the number of personnel of medical emergency teams was 14 200, with medical rescuers accounting for $70.9 \%$, nurses for $11.4 \%$, physicians for $10.3 \%$, and other staff (drivers) for 7.4\%. In 2017, emergency medical teams completed nearly 3.2 million trips/departures to the place of the incident, of which $70.7 \%$ were trips to patients' homes. In 2017, there were 1519 medical emergency teams operating in the State Medical Rescue Services (including 490 specialist and 1029 basic rescuers), 21 bases of the Medical Air Rescue Service, and 226 hospital emergency departments.

Medical emergency teams are divided into:

- specialist teams - at least 3 people allowed to perform medical rescue operations, including a physician and 2 persons: a nurse and/or a paramedic. One of the rescuers is also an ambulance driver;

- basic teams - at least 2 people allowed to perform medical rescue operations - a nurse and/or a paramedic. A physician does not belong to the basic team and, similar to the specialist team, one of the rescuers drives the ambulance;

- air rescue teams - at least 3 people, including at least 1 professional pilot, a physician, a paramedic or a nurse. Pursuant to the amended provision of Article 11 of the Act on State Medical Rescue Services [1], the profession of a medical rescuer/paramedic is primarily to provide medical services, in particular a special type of medical services, i.e., medical emergency procedures for a person in an emergency health condition. The detailed scope of activities to be performed independently by a paramedic, or under the supervision of a physician, is specified in the relevant regulation [3]. The medical emergency team transports the patient from the place of the incident to the nearest hospital emergency department, or to the hospital indicated by the medical dispatcher or the physician/ coordinator of the emergency medical rescue service. A decision to transport the patient to a distant hospital, omitting the hospital emergency department, concerns especially patients with severe and multiple injuries, eligible for treatment in an injury/trauma treatment centre or children's injury/trauma treatment centre [4,5], and patients with acute coronary syndrome or brain stroke who should be immediately directed to a hemodynamic centre or a stroke treatment emergency department [6].

Patients requiring urgent diagnosis and treatment at distant hospitals are often transported by medical air rescue teams, which significantly shortens the time of reaching the appropriate facilities and, thus, speeds up the implementation of appropriate procedures. During transport, medical activities necessary to keep the patient or the injured person alive are often carried out. The road transportation is carried out by an ambulance which, depending on the function it performs, is characterized by specific equipment [5,7].

Ambulances are divided into 3 basic types: A, B, C. This division results from the Polish Standard PN-EN 1789 + A2 "Motor vehicles and their equipment - road ambulances" [8]. Type A is an ambulance used to transport patients whose life and health are not seriously threatened, and who "are not expected to become patients in an emergency medical condition." The construction of this type of an ambulance allows distinguishing types A1 and A2. Type A1 is used to transport 1 patient in a lying position, whereas type $\mathrm{A} 2$ is used to transport $\geq 1$ patients in a sitting position. Type B is a rescue ambulance which, through its construction and fit, is used primarily to transport the patient, but also to monitor the patient's health condition and provide basic treatment. Type $\mathrm{C}$ is the socalled "mobile intensive care unit" [8]. It is an ambulance which is adapted to perform the most advanced and inten- 
sive rescue operations. Its equipment includes specialized equipment for the most difficult cases of threat to patients' health and life.

Another, and more often used, division refers to both equipment and personnel. In this division, ambulances are marked with the letters S, P, N or T. An S-designated ambulance is assigned to a specialist team (formerly a resuscitation ambulance, type R), whereas a P-designated ambulance is meant for the basic medical rescue team. The $S$ and $P$ medical rescue teams, together with medical air rescue teams, form system units which are ordered by dispatcher centers to provide medical services within the State Medical Rescue Services system. The medical dispatcher, after receiving the notification in an emergency mode, dispatches the ambulance with the shortest arrival time to the place of the incident. If necessary, paramedics of the basic team can get the support of a specialist team physician or a medical rescue helicopter physician.

The ambulance marked with the letter $\mathrm{N}$ (neonatological) is adapted to transport and resuscitate newborns and infants. Most often, N-type ambulances transport children born prematurely or children necessitating specialist treatment in intensive care units for other reasons, from less specialized to more specialized hospitals. The T-type (transport) ambulance is designed for transporting patients without the characteristics of a sudden health condition. Ambulances of this type are equipped adequately to transport a person in a lying or sitting position, and to provide oxygen therapy. However, the T-type ambulance does not have the equipment required for the State Medical Rescue Services teams, enabling the implementation of full-range medical rescue operations.

Ambulances operated in Poland (and also abroad) are characterized by a large diversity, resulting from their various applications as well as different vehicle brands they are built on. In Poland, vehicles such as Mercedes-Benz Sprinter, Mercedes-Benz Vito, Fiat Doblo, Fiat Ducato, Volkswagen Transporter, Volkswagen Crafter, Renault Trafic, and Renault Master are most often used as ambulances. These vehicles differ in dimensions and the arrangement of equipment; however, each of them should meet the requirements specified in PN-EN 1789 + A2 "Medical vehicles and their equipment - road ambulances" [8]. In the "Body" section of this standard, the minimum dimensions of the patient and treatment space are defined, as well as dimensions and the number of seats, depending on the type of the ambulance. Following these requirements is important from the point of view of safety and necessary equipment deployment. However, there is no standard or document that would specify the equipment arrangement in the ambulance so that easy access to medical materials and devices used when performing medical procedures (during the ambulance ride) is ensured, and the unification rules for the interior of the patient space regardless of the car brand are provided for. This aspect is of great importance for the efficiency and reliability of the paramedics' task performance.

Medical assistance to injured or sick patients is provided by medical rescue teams under different conditions. It is carried out at the scene of an accident, at home or during transport to the hospital, i.e., in an ambulance. Threats inherent in the work of a paramedic have a diversified nature and impact on occupational risk. Among the risk factors present in the work of a paramedic, there are physical, chemical, biological and psychosocial factors mentioned in [7,9]; some researchers add ergonomic factors as well $[10,11]$.

In the literature, one can find a classification of threats and their character but their sources are not always precisely defined. Many dissertations also concern accidents at work, to which the researchers devote special attention, analyzing their reasons to help eliminate them in the future $[9,12,13]$. The authors of this article [14] analyzed work activities carried out in an ambulance in which a medical intervention per 1 emergency call lasted 34-78 min. On average, there were $31 \mathrm{~min}$ for the duration of the am- 
bulance journey, $18 \%$ of which, i.e., 12 min, were devoted to medical procedures performed with the patient: out of which $7 \mathrm{~min}(56 \%)$ for the ambulance standing still and $5 \mathrm{~min}(44 \%)$ for active assistance provided to the patient during transport to the hospital.

According to British researchers dealing with this problem [12], on average, per 1 call for an ambulance, $1 \mathrm{~h} 52 \mathrm{~min}$ (or $24 \%$ of on-duty time) were devoted to medical activities in the ambulance cabin, of which about 81 min corresponded to the time of transport to the hospital, during which the patient remained under the care of paramedics performing the necessary procedures. Despite the difference in the presented data, the time spent in the ambulance cabin, and allocated for medical procedures during on-duty time, appeared significant. Therefore, in view of the reliable performance of life-saving activities, the problem of adapting the interior structure of ambulance patient compartments to the needs of physicians, paramedics and nurses gains increasing importance.

According to the Act of 8 September 2006 on State Medical Rescue [15], there is a "permission" in Polish legislation for not fastening seat belts by the ambulance staff. In accordance with Article 39 sec. 1 of the Road Traffic Act, road traffic participants are required to wear seat belts during the ride. However, sec. 2 pt 7 exempts from this obligation members of an emergency medical team providing medical assistance. This, of course, has certain negative consequences, such as injuries. A comparative analysis of Finnish and British paramedics [6] showed that Finnish paramedics more closely abided by the regulations reducing the risk of accident consequences by fastening seat belts (96 people - 75.6\%), whereas only 15 people, or $22.4 \%$, of British paramedics, fastened the seat belts, regardless of whether they were going to the patient or with the patient. An element considered hazardous, especially in accident situations, is the technical equipment of the ambulance interior [16], due to the lack of additional safety measures such as airbags (there are possibly only the lap belts providing a poor safety level). In addition, an ambulance medical compartment equipment consists of heavy unsecured medical equipment - unfastened or having only poorly securing straps. There are also sharp edges of various surfaces, forward facing seats, etc. Accident causes also include an incorrect organization of work [13], which indicates that increasing the efficiency of the rescue team's work also has an impact on reducing the number of accidents [9]. Knowledge of the causes of accidents makes it possible to formulate guidelines and define preventive actions that can be taken by the employer to eliminate hazards [16].

They should concern work in tight, hardly accessible places where special care should be taken. The workstation itself, i.e., the place where first aid is provided, should be adjusted so that there is convenient access to the patient and no hazards for the paramedic are present. In an ambulance, one must keep the place in good order, and all tools and objects - to be easily found - must have a designated place. It is not always possible to meet these requirements due to the dimensional diversity of the ambulance interior.

Descriptions of faulty solutions of the ambulance interior structure characterized, on the one hand, by the shortage of safety equipment elements and, on the other hand, their improper placement and no possibility to access the necessary medical equipment and materials from a sitting position can be found in many publications [14,17-20]. According to British researchers [18], approx. $48 \%$ of paramedics from among 271 respondents rated access to ambulance elements as bad on a 5-point scale (below there is only a "very bad" mark). The seating comfort was also negatively rated -116 out of 271 people marked it as bad, and 49 people as very bad. Similarly, the backrest being a structural element of the car seats, affecting the sitting comfort, was rated as very bad by 95 paramedics, and as bad by 105 of them. Musculoskeletal disorders are among the occupational health issues reported by paramedics. They come primarily from the need to transport patients on stretchers or 
rescue chairs, on an uneven surface and in limited space, and also from the necessity to assume an unnatural body posture [21]. The most frequently mentioned type of posture stress is pain in the lower back, i.e., the lumbar-sacral section of the spine $[7,11,21,22]$, followed by pain in the neck and shoulder region.

The analysis of the questionnaire surveys carried out by the Central Institute for Labour Protection - National Research Institute (Centralny Instytut Ochrony Pracy Państwowy Instytut Badawczy - CIOP PIB) [21] showed that, both in the last 7 days and 12 months before the survey, the highest percentage of female paramedic responders had experienced discomfort in the lower back (38\%, $66 \%)$, and in the neck and shoulder region $(28 \%, 53 \%)$, as well as in the upper back $(22 \%, 44 \%)$. Similar discomfort was experienced by male paramedics, and the results concerned the lower back pain $(46 \%, 65 \%)$, the neck and shoulder region $(25 \%, 45 \%)$, and the upper back $(22 \%$, $37 \%$ ). However, it should be noted here that this uncomfortable and unnatural position is not only connected with patient transport, but it often occurs also while performing medical procedures in an ambulance.

The problem of an improper interior structure of ambulances and discomfort arising therefrom occurs in many countries. Paramedics assessing ambulances operated in Malaysia [23] described the following characteristics of the ambulance as bad or very bad: the total space available $(60 \%)$, space above the head $(40 \%)$, access to the patient (43.3\%), and access to equipment in a sitting position $(50 \%)$. Polish paramedics also pointed to the issues of ambulance equipment. The research showed that the ambulances were not adapted to the amount of medical equipment components (as defined by PN-EN 1789:2008); also, the small amount of space in the ambulance was reported, hindering free movement [22].

In the surveys conducted in Israel [14], questionnaires, observations of medical procedures performed in ambulances and interviews with paramedics were used, as well as an analysis of the postures assumed by paramedics during work. The obtained results showed an improper placement of the seat, which was not conducive to the effective performance of clinical procedures. It was confirmed by $74 \%$ of the paramedics; $94 \%$ found the bench uncomfortable, and $77 \%$ thought that the distance between the bench and the stretcher was too big.

These inconveniences translated into forced and unnatural positions assumed by paramedics while performing medical procedures. In the summary, it was indicated that the interior of the ambulance was not adjusted to either paramedics or patients, and a number of design modifications were formulated. The most important ones included: replacing the bench with 2 adjustable chairs for the rescue personnel, changing the location of the medical cabinet to provide easy access, adding an adjustable folding chair opposite 2 adjustable seats, and adding a swivel base and a device for lifting the patient on a stretcher, in order to provide paramedics with better access to patients.

The last of the recommendations given also appeared in other studies [6,18], because the lack of devices to facilitate loading and unloading the stretcher increases the risk of musculoskeletal disorders. To reduce the risk of these ailments, detailed ergonomic analyses are undoubtedly required. The suggestion to use ergonomic methods in the assessment of the ambulance interior structure has also appeared in the studies on ambulances operated in Great Britain [12].

As a result of the surveys carried out in the USA and supervised by national safety institutions, an ambulance prototype was developed which, as compared to its predecessors, was modified with respect to securing cabinets and drawers, providing secure locks for heavy equipment and elements that constitute hazard for the paramedic's head. The seating position has also been changed by introducing, among others, sliding seats. Additionally, a lighting control panel, and communication and control devices were placed closer to the seats in order to reduce the need to stand up and work in a standing position. A warning 
system was also designed, which would be triggered in the event of sudden braking, in order to prepare the emergency personnel performing medical procedures for the appropriate response. Changing the interior design and the way of mounting medical equipment in the patient compartment of the vehicle should be correlated with the results of crash-tests involving ambulances.

The next step to improve the safety of medical rescue teams and reduce the need to assume a standing position in the ambulance is to introduce new equipment solutions, e.g., mechanical chest compression devices, which also have better operational efficiency while the ambulance is moving. Studies have shown that the efficiency of the compression exerted by the personnel during patient's transportation varies $0-30 \%$, whereas mechanical devices give an 88-100\% efficiency result according to the European Resuscitation Council (ERC) and American Heart Association (AHA) Guidelines 2015 [24].

In the studies carried out in the USA [25], many state institutions responsible for occupational safety in medical services got involved in the research, including the Department of Homeland Security Science and Technology Directorate States, the National Institute for Occupational Safety and Health, the National Institute of Standards and Technology, and design companies. It was found that the operated ambulances were ergonomically inefficient and often dangerous for paramedics, especially in the course of implementing medical procedures during the ambulance ride.

As a consequence, the number of accidents leading to death or serious injuries at the paramedics' workstation exceeds by far this value for an average workplace in the USA. This fact has become the premise for the development of new standards for the design of the ambulance interior structure and equipment in the patient compartment, the use of which is to ensure the safety of the emergency personnel and patients, and to facilitate the care of the patient. These activities were preceded by detailed research, whose aim was to assess the current state.
The presented analysis of the problem has shown a number of irregularities present in ambulances that reduce the efficiency of paramedics' work and increase the risk of musculoskeletal disorders, as well as the probability of an accident occurring during performing medical procedures while transporting the injured or sick person to the hospital. They are of a general nature because, according to the research, they concern ambulances in many countries. The studies of the functionality of the ambulance interior structure, conducted from the point of view of paramedics' work, confirm the necessity of developing uniform guidelines which, when used in the design process, could ensure the proper adaptation of the workstation in the rescue vehicle to the needs and capabilities of both paramedics and patients, as well as harmonize the deployment of the necessary equipment inside the ambulance.

The authors, guided by the above premises, developed a methodology for testing ambulances operated in Poland. Knowledge of the current situation, as well as the needs and expectations of paramedics, will be used to develop the principles of ergonomic design of ambulance-unified interior structures. This article presents the results of pilot studies carried out in the environment of paramedics, which set a starting point for the implementation of further steps aimed at formulating recommendations for the modification of the medical car fleet in use.

\section{MATERIAL AND METHODS}

Initial research on working conditions was carried out in Mercedes-Benz ambulances, type S and P, using a questionnaire expert survey method and a direct observation method. In each case, the medical team consisted of 2 paramedics, one of whom was also a driver. The presented research is the first stage of developing a methodology for an ergonomic assessment of the ambulance interior structure. Moreover, using the participant observation method, typical procedures performed by paramedics in a medical ambulance were recorded, i.e., cardiopulmonary resusci- 
tation and inserting a venous line. The results of an analysis of the recordings made are presented in Results.

The paper survey form included general and specific questions. On the basis of the general questions, knowledge was gained about the gender of the rescuer, height, rightor left-handedness, seniority in the profession, and the type of an ambulance in which the rescuer was usually on duty. A set of 18 detailed questions concerned the areas related to ambulance equipment, the nature of work and the inconvenience of medical procedures. Table 1 shows a set of specific questions.

From the list of questions in the article, only some were analyzed, which clearly indicate onerous working conditions.
The research was of a pilot nature and embraced 51 paramedics randomly selected from the Emergency Medical Rescue Service in Siedlce. The research was carried out in January-February 2018. The participants had different seniority, ranging 2-35 years, and, therefore, the average length of service was 14.3 years. The participants included both women and men. The group of women consisted of 5 people, which constituted $9.8 \%$ of all the participants. The group of men embraced 46 people, or $91.2 \%$. The distribution of seniority is shown in Table 2.

All the paramedics who participated in the research worked in emergency medical rescue teams, including 29 paramedics working daily in a P-type ambulance, 8 in an S-type ambulance, and 11 working alternately in an S- and P-type

Table 1. Specific questions asked to rescuers in a pilot study on the working conditions in road ambulances that embraced 51 paramedics from the Emergency Medical Rescue Service in Siedlce, Poland (January-February 2018)

\section{Questions asked}

1. What are the most common (average) medical procedures you do in an ambulance? Please indicate them in the descending order.

2. In what position are you performing your medical procedures while driving an ambulance?

3. Which procedures are easier to perform in a standing position?

4. When performing procedures in a standing position, are you secured against falling? If so, specify how.

5. Is the sitting position comfortable for medical procedures? If not, state the reason.

6. What kind of difficulties are encountered in performing medical procedures in a moving ambulance?

7. What kind of pain do you experience during and after work?

8. Which medical procedures are the most difficult for you to perform?

9. Which medical procedures in an ambulance are difficult to perform because of the lack of easy access to medical equipment?

10. Is the necessary medical equipment accessible to you in every position you assume? If not, specify which one.

11. Question for left-handed users - what is the classic arrangement of ambulance equipment? Are you comfortable with it? If not, state the reason.

12. What amenities (including additional equipment), in your opinion, would increase your comfort of working in an ambulance?

13. Do you experience any inconvenience while working in a different ambulance than usual? If so, what are they?

14. Do you think it would be advisable to unify the arrangement of the basic elements of the equipment in every ambulance regardless of its type?

15. Please specify which modifications of the spatial structure (interior) of the ambulance would raise your work comfort.

16. Is the lighting in the ambulance sufficient for the medical procedures to be performed?

17. Is the arrangement of the ambulance equipment the same regardless of the vehicle model?

18. If the arrangement of the equipment in different ambulances is not the same, how long does it take you to get acquainted with it before you are ready to work? 
Table 2. Distribution of seniority among the research participants in a pilot study on the working conditions in road ambulances that embraced 51 paramedics from the Emergency Medical Rescue Service in Siedlce, Poland (January-February 2018)

\begin{tabular}{|c|c|c|c|}
\hline \multirow[t]{2}{*}{ Seniority } & \multicolumn{3}{|c|}{$\begin{array}{c}\text { Participants } \\
(\mathrm{N}=51) \\
{[\mathrm{n}]}\end{array}$} \\
\hline & total & $\begin{array}{l}\text { females } \\
(\mathrm{N}=5)\end{array}$ & $\begin{array}{c}\text { males } \\
(\mathrm{N}=46)\end{array}$ \\
\hline $0-10$ years & 14 & 0 & 14 \\
\hline $11-20$ years & 30 & 5 & 25 \\
\hline $21-30$ years & 2 & 0 & 2 \\
\hline$\geq 31$ years & 5 & 0 & 5 \\
\hline
\end{tabular}

ambulance. The tests were anonymous and were conducted with the consent of the Head of Emergency Medical Rescue Service in Siedlce. The obtained results were coded in MS Excel 2010 and developed statistically using the Statistica version 8 software.

\section{RESULTS}

\section{Questionnaire expert surveys}

The results obtained from the questionnaires revealed many irregularities present in ambulances. This article presents selected issues closely related to the paramedics' working conditions. In the research area regarding inconveniences related to work in an ambulance, the participants mainly indicated the necessity of assuming a standing position while performing medical procedures, and thus the lack of protection against falling during the ambulance ride. An analysis of the responses showed that 36 out of 51 paramedics performed medical procedures in a standing position, and only 9 in a sitting position. The others worked in both positions interchangeably (Figure 1).

Performing medical procedures in a standing position is a great threat to the life and health of paramedics when the procedures are carried out while the ambulance is moving. In some rescue ambulances, there are fall protection devices installed, e.g., in the form of a protective net, but this solution is not obligatory. In the research,
24 medical rescuers mentioned ambulance safety equipment in their responses, whereas 26 confirmed the lack of such equipment. Out of 24 people, 18 mentioned a protective net mounted next to the side seat; 4 paramedics indicated a handrail located on the car ceiling as a fall protection device, and 3 medical rescuers indicated spreading legs far apart as a security feature. In addition, members of the ambulance crews pointed out that the existing protective net and railing did not provide any support for the paramedic standing at the patient's head.

Difficulties in performing certain medical procedures resulting from the presence of the mentioned fall protection devices were also found.

Assuming an inconvenient, forced body position when performing standing or sitting work, e.g., with upper limbs above the shoulder level, and keeping such a position for a long time, can cause many injuries and musculoskeletal disorders. More than half of the respondents (29 persons) stated that they experienced back pain while performing work. They also reported pain in the ankle joints, wrist pain, bruises, contusions, limb cramps, aches of muscles, arms, shoulders, loins, and lower limbs. Figure 2 presents the percentage share of pain occurring in the examined ambulance rescuers.

The respondents were also asked about the subjective feelings associated with the ambulance equipment. To the 


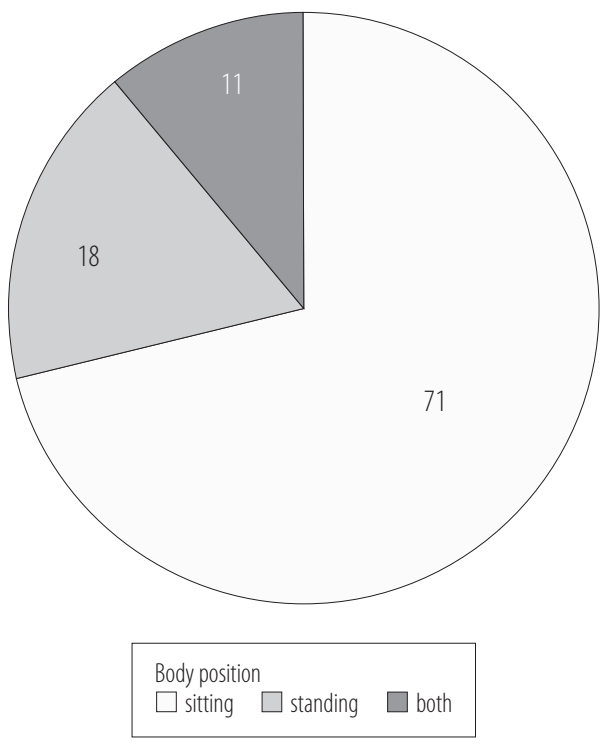

Figure 1. The number of paramedics assuming various body positions in the course of performing medical procedures while the ambulance is moving, in a pilot study on the working conditions in road ambulances that embraced 51 paramedics from the Emergency Medical Rescue Service in Siedlce, Poland (January-February 2018)

question: "Is the necessary medical equipment accessible to you in every position you assume? If not, specify which one," more than half of the respondents $(53.5 \%)$ replied that, regardless of the position assumed, not every item of equipment was accessible. Most often, it was pointed out that there was no problem to access the equipment in a standing position, while in a sitting position the access was limited, which may happen when the patient's condition during the journey requires the rapid use of "restricted availability" medical materials.

During the analysis of the research results, it was noticed that the problem was not only related to equipment accessibility, but also to its arrangement in various types of vehicles. The variety of interior ambulance structure solutions causes difficulties at work.

As many as 18 out of 51 examined paramedics experienced discomfort or inconvenience during an on-call service in an ambulance other than their usual one. In the case of changing the ambulance assignment, paramedics must be-

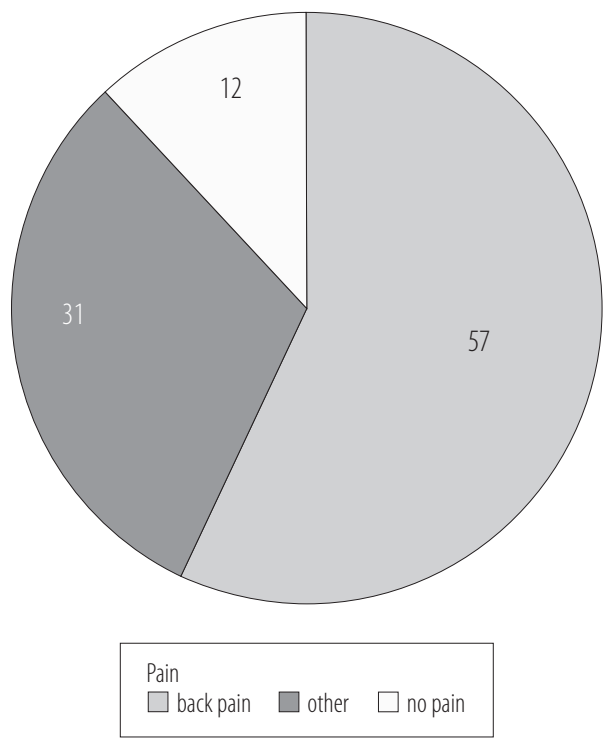

Figure 2. The number of paramedics experiencing various types of pain, in a pilot study on the working conditions in road ambulances that embraced 51 paramedics from the Emergency Medical Rescue Service in Siedlce, Poland (January-February 2018)

come acquainted with the arrangement of individual pieces of equipment (devices, medical supplies, medicines) at the beginning of their on-call duty. This is very cumbersome and time-consuming.

The average time spent on these activities was defined to be $33 \mathrm{~min}$. The paramedics also underlined the fact that getting acquainted with a new workplace was not tantamount to memorizing the arrangement of individual elements. During paramedics' work, as it is necessary to implement procedures quickly and efficiently, these are often the routine and automatic reactions that prevail. They are of no use in an unfamiliar interior structure, which leads to a longer time needed to perform particular activities. Table 3 shows the times needed to understand the location of ambulance equipment.

The authors investigated the correlation between the seniority of paramedics (y) and the time necessary for familiarization with the new vehicle interior (x). Pearson's product moment correlation coefficient (or Pearson's r) was used in the research. This coefficient is used to study 
Table 3. Time necessary for becoming acquainted with the deployment of equipment in the ambulance interior, in a pilot study on the working conditions in road ambulances that embraced 51 paramedics from the Emergency Medical Rescue Service in Siedlce, Poland (January-February 2018)

\begin{tabular}{|c|c|}
\hline Time & $\begin{array}{c}\text { Participants } \\
(\mathrm{N}=51) \\
{[\mathrm{n}]}\end{array}$ \\
\hline $0-10 \mathrm{~min}$ & 18 \\
\hline $11-20 \mathrm{~min}$ & 17 \\
\hline $21-30 \mathrm{~min}$ & 9 \\
\hline $31-40 \mathrm{~min}$ & 0 \\
\hline $41-50 \mathrm{~min}$ & 0 \\
\hline $51-60 \mathrm{~min}$ & 2 \\
\hline$\geq 60 \mathrm{~min}$ & 5 \\
\hline
\end{tabular}

the relations in which an increase in the value of one of the features causes proportional changes in the average value of the second feature. Like other correlation coefficients, Pearson's $r$ may vary from -1 to 1 . Extreme values, i.e., -1 and 1 , indicate a perfect correlation between the variables studied. The result equal to 0 means that the values of these 2 variables do not coincide (no correlation). Pearson's $r$ can be considered in the following ranges: 0-0.3 - a poor correlation; $0.3-0.5$ - a moderate correlation; $0.5-0.7$ - a strong correlation; $0.7-1$ - a very strong correlation [25]. In order to calculate the value of Pearson's correlation coefficient for 2 variables, designated as $\mathrm{x}$ and $\mathrm{y}$, formula 1 was used:

$$
\mathrm{r}_{\mathrm{xy}}=\frac{\frac{1}{\mathrm{n}} \sum_{\mathrm{i}=1}^{\mathrm{n}}\left(\mathrm{x}_{\mathrm{i}}-\overline{\mathrm{x}}\right)\left(\mathrm{y}_{\mathrm{j}}-\overline{\mathrm{y}}\right)}{\mathrm{s}(\mathrm{x}) \mathrm{s}(\mathrm{y})}
$$

where:

$r_{x, y}$ - Pearson's correlation coefficient,

$x_{i}, y_{i}-$ values of the features of ith and jth observations,

$\bar{x}, \bar{y}-$ average variables values,

$\mathrm{n}$ - sample size,

$\mathrm{s}(\mathrm{x}), \mathrm{s}(\mathrm{y})$ - standard deviations.
As a result of calculations, average values $\overline{\mathrm{x}}=24.88$; $\bar{y}=14.33$ and standard deviations $\mathrm{SD}_{\mathrm{x}}=17.13, \mathrm{SD}_{\mathrm{y}}=6.80$ were determined. Pearson's correlation coefficient was $r_{x, y}=-0.15$. On the one hand, the sign of the coefficient indicates a negative correlation between the analyzed variables. On the other hand, the absolute value of the measurement speaks of the lack of dependence between both features.

The next step was to check whether the calculated correlation was statistically significant.

$$
\begin{gathered}
\mathrm{H}_{0}: \mathrm{q}=0 \\
\mathrm{H}_{0}: \mathrm{q} \neq 0 \\
\mathrm{t}_{\text {emp }}=\frac{\mathrm{r} \sqrt{\mathrm{n}-2}}{\sqrt{1-\mathrm{r}^{2}}}
\end{gathered}
$$

where:

$\mathrm{r}$ - Pearson's correlation coefficient,

$\mathrm{n}$ - number of tests.

The authors assumed the level of significance: $\mathrm{a}=0.05$, $\mathrm{r}_{\mathrm{x}, \mathrm{y}}=-0.15$

Hence:

$$
\mathrm{t}_{\mathrm{emp}}=\frac{\mathrm{r} \sqrt{\mathrm{n}-2}}{\sqrt{1-\mathrm{r}^{2}}}=-1.06
$$

The critical value is calculated for quantiles:

$$
1-\frac{0.05}{2}=0.975
$$

and

$$
\mathrm{n}-2=51-2=49 \text { degrees of freedom }
$$

From the Student's t-boards: $\mathrm{T}_{\text {kryt }}=2.00$.

The critical area has a form:

$$
(-\infty ;-2>\cup<2 ;+\infty)
$$


Test statistics do not belong to the critical area, i.e., there is no correlation between the length of service and the age of rescuers.

In connection with the above, it was found that there was no dependence between seniority and the time of familiarizing with the new interior of the vehicle. This means that the years of service and the experience gained did not shorten the time of adapting to an unfamiliar ambulance equipment deployment. The graphical interpretation of the correlation is the so-called scatterplot, which is shown in Figure 3.

The questionnaire also included questions regarding proposals for modifying the structure of the vehicle interior.

The responses were very detailed and extensive, and attention was drawn mainly to several areas, presented in the order of importance: the unification of equipment and interior development, the necessary implementation of a system to protect paramedics from falling during work in a standing position while the ambulance is moving, increased space in ambulances allowing for the possibility of accessing the patient from both sides, and a modified cabinet construction - cabinets supplemented with descriptions, compartments and interior lighting. The research shows that the problem of equipment unification is particularly important from the point of view of paramedics' work. As many as $90 \%$ of the participants regarded unification of the equipment deployment desirable.

It was pointed out that such unification should concern P- and S-type ambulances. The unification would significantly reduce the paramedics' work discomfort and stress associated with uncertainty regarding the deployment of equipment. Above all, it would shorten the time that the paramedics need to familiarize themselves with interior equipment.

A few years ago, paramedics of the Medical Air Rescue Service faced similar problems. This is why the purchase of helicopters was preceded by ergonomic research, which led, at the construction stage, to the optimization of de-

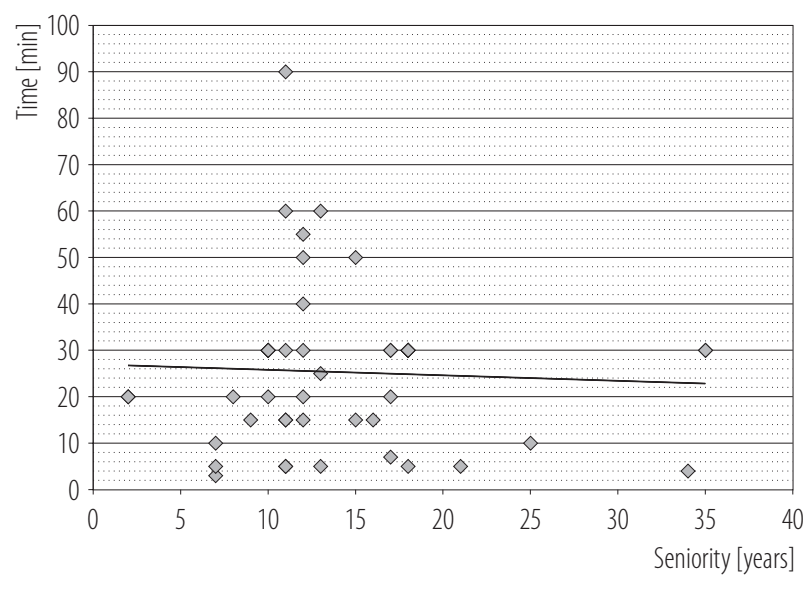

Figure 3. The correlation (along with the trend line) between seniority and the time necessary to become acquainted with the deployment of equipment in the ambulance, in a pilot study on the working conditions in road ambulances that embraced 51 paramedics from the Emergency Medical Rescue Service in Siedlce, Poland (January-February 2018)

ployment of medical equipment and necessary medical materials in the helicopter medical compartment. Currently, all rescue helicopters are unified which results in an identical placement of medical equipment in all machines. Also, further actions have been taken to standardize the equipment of rescue backpacks in such a way that in each helicopter stationed in one of the 21 bases the distribution of drugs and medical materials would become identical. Thanks to these solutions, if a paramedic being a member of the HEMS crew is on duty at a base other than his/her own, he or she works in identical conditions.

\section{Observation of procedures performed in simulated conditions}

By means of direct observation, the work of paramedics was monitored in a simulated event in an ambulance. The analysis concerned the procedure of cardiopulmonary resuscitation performed in the case of sudden cardiac arrest (SCA). The very diagnosis of SCA as well as the series of subsequent activities to be performed required from the team members a forced standing position, which is not safe when working in a moving ambulance. 
The standing posture requires unfastening the seat belts. A paramedic, in a standing position, often performs procedures involving both hands, such as compressing the chest, connecting the defibrillator electrodes or even reaching for equipment or medicines stored in cabinets. This affects the balance of a paramedic assuming a standing posture while the ambulance changes the speed, in particular, while decelerating. As can be seen in the film, paramedics' attempt to keep a stable position through the increased leaning of the lower limbs against the transport stretcher can lead to injuries and bruising. This is not only dangerous for the paramedics, but it can also affect the precision of the medical procedure.

Placing small medical equipment in cabinets under the ceiling when the patient cannot be accessed from both sides makes it virtually impossible to reach this equipment from a sitting position. This concerns both the side seat and the seat by the patient's head. It is also worth underlining that even in a seated position it is difficult to perform some procedures, not only because of the shocks the ambulance generates during the ride, but also because of the lack of space to collect the equipment necessary to perform the procedure.

A paramedic wanting to insert a venous line while the ambulance is moving must assume a standing position in order to collect the necessary equipment. Then, when he or she has again assumed a sitting position in the side seat, the paramedic must put the equipment in one place before starting the procedure. There is no stable table/tray around where the equipment could be placed. Therefore, the paramedic puts the necessary accessories on the seat while assuming the squatting position behind the seat.

In the case of sudden braking, this can, of course, lead to numerous injuries, especially of the head, neck and chest. After inserting the venous line, the paramedic must place the used equipment in a suitable container, which again requires assuming a vertical position and moving towards the medical ambulance front compartment. The above- described inconveniences are only some examples, and there are many others that should be carefully examined and systematized. There is no doubt that safety and comfort of work of medical emergency teams translates into the well-being and safety of patients; therefore, further research in this area seems necessary.

\section{DISCUSSION}

The pilot questionnaires and expert surveys included 51 paramedics of various work seniority. The research was aimed at identifying current problems occurring while working in selected ambulances used in Poland. The same problems were also identified while observing paramedics performing selected procedures in simulated conditions. The obtained preliminary results allow the conclusion that the observed difficulties at work, resulting from an improper development of medical compartments of ambulances, are also present in other countries. Numerous examples of research conducted in Great Britain, Finland, Israel, Australia, Malaysia and the USA, quoted in the introduction to the article, confirm the validity of the adopted direction of the research. In many cases, the lack of fall protection devices for paramedics while driving an ambulance, difficult access to the patient and difficult access from a sitting position to the necessary equipment, medicines or medical materials have been demonstrated. The research shows the common risk - present in many countries - of musculoskeletal disorders and the possibility of an accident occurring while performing medical procedures on the way to the hospital.

Research in this area was also conducted by CIOP at the request of the Social Insurance Institution in 2012-2013, where, among others, ailments experienced by paramedics of both sexes in the last 12 months before the tests were analyzed [21]. These results are in line with the results of the pilot studies.

American studies [20] have shown a significant correlation between the low ergonomic level of ambulance worksta- 
tions and the recorded number of accidents at work, which exceeds that of an average workplace in the USA. This fact has led to work on standards for the design and unification of the spatial structure and ambulance equipment, which will undoubtedly lead to increased safety for both the rescuer and the patient.

The introduction of harmonized guidelines in Polish legislation leading to unification would significantly reduce the discomfort in the work of a paramedic and the stress associated with the uncertainty about the deployment of equipment. Above all, it would reduce the time that paramedics devote to familiarizing themselves with the interior of a vehicle.

A few years ago, similar problems were encountered by the rescuers of the Air Rescue Service. Therefore, the purchase of new helicopters was preceded by ergonomic research, which led, at the design stage, to the optimal placement of medical equipment and necessary medical materials in the helicopter medical compartment. Currently, all rescue helicopters are unified and the result is a uniform distribution of medical equipment in all machines.

Going further, actions were taken to standardize the equipment of rescue backpacks in such a way that in each helicopter stationed in one of the 21 bases the distribution of drugs and medical materials was identical. Thanks to these solutions, if a paramedic is on duty in a different base than the home base, he or she works in the same conditions.

The analysis of the problem shows that it was found in many studies that the ambulance interior structure was not properly adapted to the tasks performed, but only in a few cases specific modifications were proposed.

\section{CONCLUSIONS}

Changes to the ambulance interior design are necessary, but the procedures for their implementation require systematization. As a result of detailed research and ergonomic analyses, legal acts should be adopted to formulate the principles for equipping ambulances, from the point of view of adapting them to the psychophysical needs of paramedics and the nature of their work. These steps would allow for the unification of interiors regardless of the vehicle brand based on which the ambulance was built. Pilot studies have shown that familiarizing oneself with the new interior in the case of working in an ambulance other than usual requires additional time, although it does not guarantee a faultless localization of the equipment while carrying out rescue tasks. In the "Body" section of PN-EN $1789+$ A2 "Medical vehicles and their equipment - road ambulances," minimum dimensions are specified defining the patient and treatment space, dimensions and the number of seats, depending on the type of the ambulance. However, these requirements are not sufficient to design an ergonomic interior that guarantees comfort and work reliability to members of emergency medical teams.

The presented research is a starting point for the development and implementation of the methodology of comprehensive research on the spatial structure of an ambulance, including the acquisition of detailed data. Implementation of further research should be preceded by a detailed analysis of the procedures and types of ambulances used. Formulating recommendations to improve the current state would require an assessment of the ergonomic level of existing solutions for the spatial structure of medical compartments in functioning ambulances. For this purpose, subjective, objective and estimated methods should be used to enable, among others, the assessment of physical effort, risk assessment related to musculoskeletal load (e.g., rapid upper limb assessment [RULA], rapid entire body assessment [REBA], or the Ovako Working posture Analysis System [OWAS]), an assessment of muscle load and fatigue during the performance of medical procedures using surface electromyography, an assessment of the kinematics of rescue movement during work, as well as an anthropometric verification of medical compartment di- 
mensions with the use of available simulation packages. The analysis of the obtained results is likely to facilitate an assessment of the ergonomic level of the examined objects and proposing directions for their modification, followed by the development of uniform guidelines for manufacturers, the application of which will ensure the production of unified ambulances.

\section{REFERENCES}

1. [Act of 8 September 2006 on State Medical Rescue. J Laws 2006, No. 191, item 1410]. Polish.

2. Central Statistical Office [Internet]. Warsaw: The Office; 2017 [cited 2019 Jan 10]. [Emergency aid and medical rescue]. Available from: https://stat.gov.pl/obszary-tematyczne/ zdrowie/zdrowie/pomoc-dorazna-i-ratownictwo-medyczne-w2017-roku,14,2.html. Polish.

3. [Regulation No. 64/2016/DSM of the President of the National Health Fund of 30 June 2016 on determining the conditions for the conclusion and implementation of contracts in the form of emergency medical services. J Laws 2016, No 64]. Polish.

4. [Regulation of the Minister of Health of 25 January 2016 on an injury centre for children. J Laws 2016, item 145]. Polish.

5. [Regulation of the Minister of Health of 18 June 2010 on an injury centre. J Laws 2010, No. 118, item 803]. Polish.

6. Auvinen T, Lisitsyn D. Study of Paramedic Staff Safety Comparing Greater Manchester and Finland (bachelor thesis) [Internet]. Lappeenranta: Saimaa University of Applied Sciences Health Care and Social Services; 2017 [cited 2018 Nov 30]. Available from: https://www.theseus.fi/handle/10024/137789.

7. Wnukowski K, Kopański Z, Sianos G. [Specificity of work of paramedic]. JCHC. 2015;3:2-9. Polish.

8. PN-EN 1789+A2:2015-01 [Medical vehicles and their equipment - Road ambulances]. Warszawa: Polish Committee for Standardization; 2015. Polish.

9. Gałązkowski R, Binkowska A, Samoliński K. Occupational injury rates in personnel of emergency medical service. Ann Agricult Environ Med. 2015;22(4):625-9.
10. Kulczycka K, Grzegorczyk-Puzio E, Stychno E, Piasecki J, Strach K. [Effect of work on general wellbeing of paramedics]. Med Ogólna Nauki Zdr. 2016;22(1):66-71. Polish.

11. Wnukowski K, Kopański Z, Brukwicka I, Sianos G. [The danger of medical rescue work - selected issues]. JCHC. 2015;3:10-6. Polish.

12. Ferreira J, Sue Hignett S. Reviewing ambulance design for clinical efficiency and paramedic safety. Appl Ergon. 2005;36:97-105.

13. Garus-Pakowska A, Gaszyńska E, Szatko F. [The incidence of accidents at work among paramedics in the years 20012013 based on the register of one selected hospital]. Med Pr. 2016;67(2):213-21, https://doi.org/10.13075/mp.5893.00351. Polish.

14. Gilad I, Byran E. Ergonomic evaluation of the ambulance interior to reduce paramedic discomfort and posture stress. Hum Factors. 2008;49(6):1019-32, https://doi.org/10.1518/ $001872007 X 249884$.

15. [Act of 8 September 2006 on State Medical Rescue. J Laws 2006, No. 191, item 1410]. Polish.

16. Fedorczuk W, Pawlas K. [Occupational risk factors of a medical rescue worker]. Hygeia Public Health. 2011;46(4):43741. Polish.

17. Institut de recherche Robert-Sauvé en santé et en sécurité du travail [Internet]. Montral: 2017 [cited 2018 Nov 30]. Measurement of emergency medical technician-paramedics' exposure to musculoskeletal risk factors, report R-944. Available: http://www.irsst.qc.ca/media/documents/PubIRSST/ DS-999.pdf.

18. Ambulance Paramedics of British Columbia [Internet]. Richmond [cited 2018 Dec 10]. 2001 Evaluation of Paramedics Tasks and Equipment to Control the Risk of Musculoskeletal Injury (final report GRANT 99FS-14). Available from: https://pdfs.semanticscholar.org/b342/96a906dc66fa7e a76b23f189765031bfab9b.pdf.

19. Green JD, Ammons DE, Isaacs AJ, Moore PH, Whisler RL, White JE. Creating a safe work environment for emergency medical service workers. ASSE Professional Development 
Conference and Exhibition, 9-12 June; Las Vegas; Nevada, Conference Proceedings.

20. Levick N, Grzebieta R. Crashworthiness analysis of three prototype ambulance vehicles. Int Enhanc Safety Vehicles. 2007;07-0249:2-7.

21. ZUS [Internet]. Warsaw: The Institution; 2013 [cited 2018 Sep 12]. Available from: https://www.zus.pl/documents/ 10182/167782/Badanie+i+ocena+obci\%C4\%85\%C5\%BC enia + prac\% $44 \% 85+$ os $\% \mathrm{C} 3 \% \mathrm{~B} 3 \mathrm{~b}+$ zatrudnionych $+\mathrm{w}+\mathrm{ra}$ townictwie + medycznym $+\mathrm{i}+$ pomocy + spo $\%$ C5\% $\% 2$ ecznejmin_2.pdf/e9d37316-699d-443f-97b8-ffc978a7b565.

22. ZUS [Internet]. Warsaw: The Institution; 2013 [cited 2018 Nov 15]. Available from: https://www.zus.pl/docu ments/10182/39564/Materia\%C5\%82y+informacyjne+do tycz\%C4\%85ce+prewencji+wypadkowej+i+profilaktyki+ nadmiernego+obci $\% \mathrm{C} 4 \% 85 \% \mathrm{C} 5 \% \mathrm{BCenia}+\mathrm{uk} \% \mathrm{C} 5 \% 82 \mathrm{a}$ $\mathrm{du}+$ ruchu+ratownik $\% \mathrm{C} 3 \% \mathrm{~B} 3 \mathrm{w}+$ medycznych $+\% 289 \% 2$ C64+MB\%29+-+2013+r..pdf/a5c441ed-8198-45e0-8ecedb9e54a9a483.

23. Rosnah MY, Malik A, Zainal A, Agamohamadi F. Task analysis of paramedics in the Ambulance Patient Compartment. Adv Eng Forum. 2013;10:278-84.

24. American Heart Association [Internet]. The Association; 2015 [cited 2019 Jan 10]. [Aktualizacja wytycznych AHA w zakresie resustytacji krążeniowo-oddechowej i doraźnego postępowania w zaburzeniach krążenia z 2015 r.]. Available from: https://eccguidelines.heart.org/wp-content/up loads/2015/10/2015-AHA-Guidelines-Highlights-Polish. pdf. Polish

25. Sobczyk M. Statistics. Warsaw: PWN; 2007.

This work is available in Open Access model and licensed under a Creative Commons Attribution-NonCommercial 3.0 Poland License - http://creativecommons.org/ licenses/by-nc/3.0/pl/deed.en. 